\title{
Accumulation of Phenylpropanoids in Tartary Buckwheat (Fagopyrum tataricum) under Salt Stress
}

\author{
Nam Su Kim ${ }^{1, \dagger}$, Soon-Jae Kwon ${ }^{2,+}{ }^{\oplus}$, Do Manh Cuong ${ }^{1}$, Jin Jeon ${ }^{1}$, Jong Seok Park ${ }^{3}$ and \\ Sang Un Park ${ }^{1, *}$ \\ 1 Department of Crop Science, Chungnam National University, 99 Daehak-ro, Yuseong-gu, \\ Daejeon 34134, Korea; kns917555@gmail.com (N.S.K.); domanhcuong87hy@gmail.com (D.M.C.); \\ jeonjin519@gmail.com (J.J.) \\ 2 Korea Atomic Energy Research Institute, Advanced Radiation Technology Institute, 29 Geumgu-gil, \\ Jeongeup-si, Jeollabuk-do 56212, Korea; soonjaekwon@kaeri.re.kr \\ 3 Department of Horticultural Science, Chungnam National University, 99 Daehak-ro, Yuseong-gu, \\ Daejeon 34134, Korea; jongseok@cnu.ac.kr \\ * Correspondence: supark@cnu.ac.kr; Tel.: +82-42-821-5730; Fax: +82-42-822-2631 \\ + Nam Su Kim and Soon-Jae Kwon contributed equally to this work.
}

Received: 22 September 2019; Accepted: 6 November 2019; Published: 11 November 2019

\begin{abstract}
Salinity stress affects plants by reducing the water potential and causing ion imbalance or disturbances in ion homeostasis and toxicity. Salinity stress frequently causes both osmotic and ionic stress in plants, resulting in the increase or decrease of certain secondary metabolites in plants. In this study, the effect of $\mathrm{NaCl}$ treatment on the nutritional quality of tartary buckwheat plants was studied by conducting an HPLC analysis of phenylpropanoid and anthocyanin content. It was observed that there was no significant change of color in tartary buckwheat during salt treatment. The accumulation of most phenylpropanoid compounds increased slightly in response to the $\mathrm{NaCl}$ concentration. The total phenylpropanoid content in tartary buckwheat was the highest at $100 \mathrm{mM}$ $\mathrm{NaCl}$ treatment. Seven-day-old wheat plantlets treated with $100 \mathrm{mM} \mathrm{NaCl}$ for 2, 4, 6, and 8 days showed the highest accumulation of total phenylpropanoids at day 8 after treatment, while the content of most phenylpropanoids was higher than that in the control during this period. Although the development of tartary buckwheat slightly decreased with $\mathrm{NaCl}$ treatment and the accumulation of anthocyanin compounds did not change in plants with a diffident $\mathrm{NaCl}$ concentration and time treatment, the results suggest that the salinity treatment of tartary buckwheat causes antioxidant activity improvement by inducing an accumulation of flavonoid and phenolic compounds. However, since the anthocyanin content did not increase, the antioxidant effect of the treatment is not expected to be significant.
\end{abstract}

Keywords: tartary buckwheat; phenylpropanoid; anthocyanin; salinity stress; $\mathrm{NaCl}$

\section{Introduction}

High salinity stress induces osmotic stress and removes water from the cytoplasm, causing cell dehydration, which reduces the vacuole volume and cytoplasm. It is required for plants to cope with two main kinds of stress, namely, ionic stress and osmotic stress against high salinity. Osmotic stress indicates that salinity levels rise outside the roots and immediately reach the plant by inhibiting water ingestion, cell swelling, and subsequent bud development [1]. Ionic stress results from an excess of toxic ions, such as $\mathrm{Na}^{+}$, which leads to an increase in the chlorophyll content and necrosis of leaves and a decrease in essential cell metabolic activities, including photosynthesis [1,2]. Salinity stress frequently causes both osmotic and ionic stress in plants, resulting in an increase or decrease of certain secondary 
metabolites in plants [3]. Anthocyanins have been reported to accumulate under salinity stress [4]. In contrast, salinity stress decreases the accumulation of anthocyanin in salinity-sensitive plants [5]. For example, proline accumulates doubly fast in the roots of alfalfa, a halophyte, when compared with the situation in glycophytes [6]. In tomato (Solanum lycopersicum) cultivars under salinity stress, the accumulation of endogenous jasmonic acid was increased [7]. The accumulation and synthesis of phenolic compounds usually increase the levels of physiological or nervous activity in response to plant stress $[8,9]$. It has been reported that the accumulation of phenolic compounds in other tissues increased under an increasing salt concentration in many plants [10]. It has also been reported that red peppers under moderate salinity show an increased accumulation of total phenolic compounds [11].

Unlike most cereals, common buckwheat (Fagopyrum esculentum), which belongs to the Polygonaceae family, is usually used as an alternative cereal. Buckwheat seed can be stored for a long time, without significant chemical alteration, because it contains antioxidant phytochemicals, such as phenolic acids, flavonoids, and tocopherols [12]. Rutin, which is a flavonol glycoside plant metabolite, has anti-inflammatory, anticarcinogenic, and antioxidant properties. It can also decrease the fragility of blood vessels associated with hypertension and hemorrhagic disease in humans [13]. Buckwheat has more rutin than most plants. Isovitexin and rutin are the only described flavonoids of buckwheat seed. Buckwheat hulls also have rutin, orientin, quercetin, isoorientin, vitexin, and isovitexin [12]. Differences in the antioxidant properties of buckwheat are mostly due to the cultivars and environmental effects [13]. Common buckwheat (Fagopyrum esculentum) and tartary buckwheat (Fagopyrum tataricum) are two major varieties of buckwheat. Common buckwheat and tartary buckwheat are used worldwide. Common buckwheat seeds have between 0.13 and $0.36 \mathrm{mg}$ rutin/g dry weight (DW); in contrast, tartary buckwheat seeds have between 7 and $8 \mathrm{mg}$ rutin/g DW [14,15]. Furthermore, tartary buckwheat sprouts contain between 50 and $60 \mathrm{mg}$ rutin/g DW-2.2 folds higher than that of similarly cultivated common buckwheat sprouts [16].

Phenylpropanoids are a group of organic compounds synthesized by plants from the amino acids phenylalanine and tyrosine [17]. This group's name indicates the presence of six carbons in the structure of the member compounds. The aromatic phenyl group and 3-carbon propene tail of coumaric acid are the main intermediates in phenylpropanoid biosynthesis. From 4-coumaroyl-CoA, numerous natural products are biosynthesized, such as lignols, isoflavonoids, aurones, catechin, flavonoids, stilbenes, coumarins, and phenylpropanoids (Figure 1) [18]. Phenylpropanoids, found in many plants, defend plants from pathogens and herbivores; protect them from ultraviolet light; and mediate plant-pollinator interactions, acting as scent compounds and floral pigments. The flavonoid synthesis pathway mainly includes derivatives such as flavonols, anthocyanins, and proanthocyanins [19-21]. Their antioxidant properties and structural variety play a physiological role when plants interact with biological and abiotic environments [19,22-26]. Furthermore, studies on the correlation between diverse hormones and flavonoids in the regulation of developmental processes, including seed size and fertility, are gaining attention $[22,27,28]$. These phenylpropanoids are responsible for the agricultural, nutritional, and industrial value of crops. Flavonoids affect the quality of food, fruit, and seed and the astringency of the plant product $[26,27]$. These phenylpropanoids are good models for an analysis of the extensive diversity of genetic, epigenetic, cellular, and biochemical processes, because of their variety and ease of isolation. It is supposed that they establish the well-studied metabolic and regulatory pathways in plants [29].

In this study, we investigated the change in metabolomics of tartary buckwheat under salinity treatment using various concentrations of $\mathrm{NaCl}$ and different treatment times. Using an HPLC analysis system, the accumulation of phenylpropanoids and anthocyanins under $\mathrm{NaCl}$ treatment was studied. This study provides deeper insights into the change in metabolomics of tartary buckwheat under salinity stress. 


\section{Materials and Methods}

\subsection{Plant Materials}

Daegwan No.3-3 seeds, representing one tartary buckwheat cultivar, which were provided by the Rural Development Administration (RDA), Korea, were used for this experiment. The soil used this experiment was horticultural soil and buckwheat seeds were sown in pots. $\mathrm{NaCl}$ aqueous solution was made with distilled water and sodium chloride. Buckwheat seedlings, which were 7 days old, were treated with different $\mathrm{NaCl}$ concentrations $(0,100,200$, and $300 \mathrm{mM})$ in a plant chamber under $16 \mathrm{~h} / 8 \mathrm{~h}$ (light/dark) condition at $25^{\circ} \mathrm{C}$. After treatment for 4 weeks, buckwheat seedlings were harvested to investigate the response to salinity stress. For time treatment experiments, we sowed the seeds in pots and these seeds were grown in a plant chamber for 6 weeks at the temperature of $25{ }^{\circ} \mathrm{C}$ and a $16 \mathrm{~h} / 8 \mathrm{~h}$ (light/dark) condition. Buckwheat, which was 6 weeks old, was treated with $100 \mathrm{mM} \mathrm{NaCl}$ at different times for finding the optimal treatment time. The samples were harvested on days 2, 4, 6, and 8 after treatment, and all samples were put in liquid nitrogen and then freeze-dried for an analysis of the phenylpropanoid and anthocyanin content.

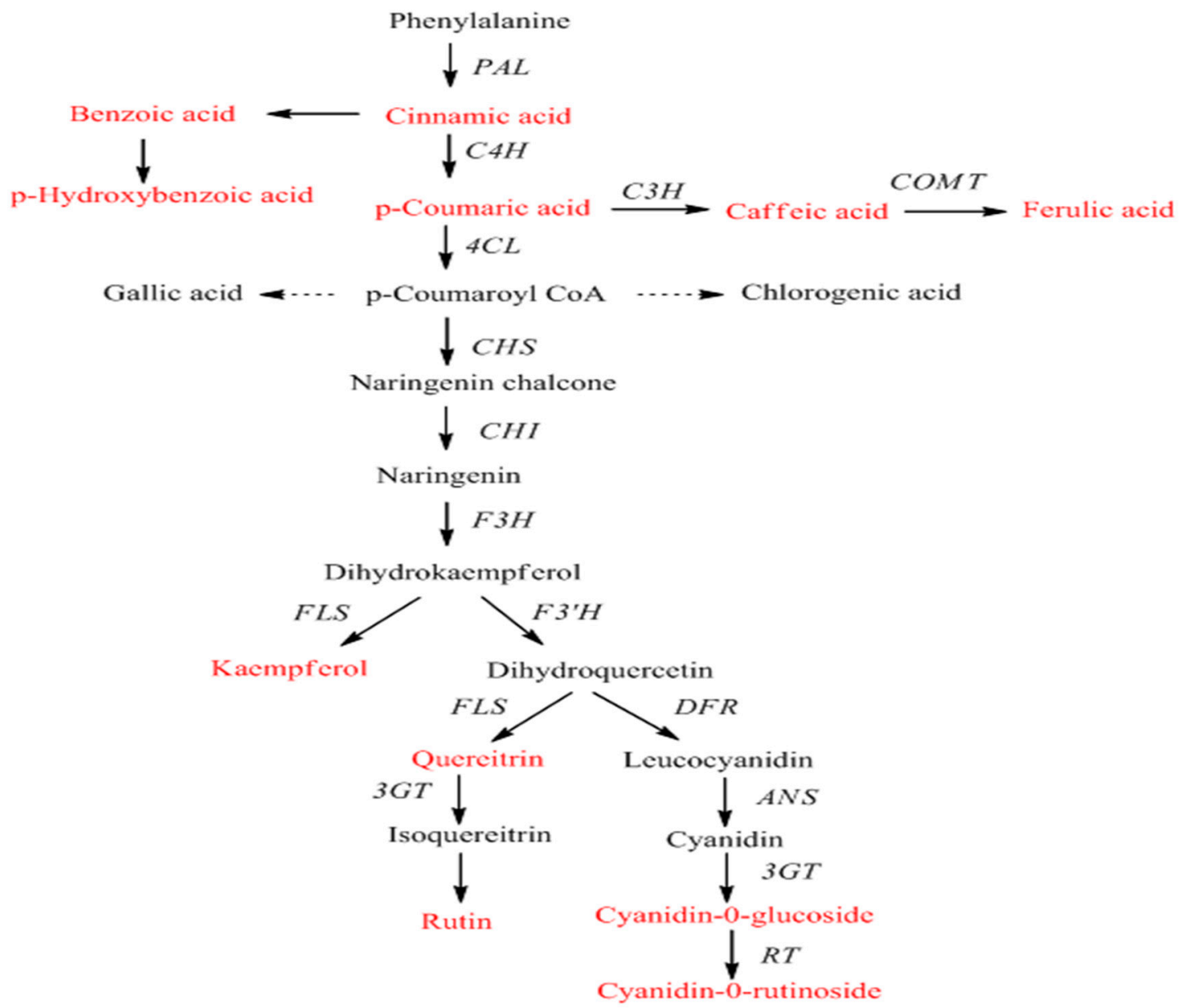

Figure 1. Schematic representation of flavonoid biosynthesis in tartary buckwheat. PAL, phenylalanine ammonium lyase; $\mathrm{C} 4 \mathrm{H}$, cinnamic acid 4-hydroxylase; 4CL, 4-coumarate-CoA ligase; $\mathrm{CHS}$, chalcone synthase; $\mathrm{CHI}$, chalcone isomerase; F3H, flavanone-3-hydroxylase; F3' $\mathrm{H}$, flavonoid-3'-hydroxylase; FLS, flavonol synthase; DFR, dihydroflavonol reductase; ANS, anthocyanin synthase; 3GT, flavonoid 3-O-glucosyltransferase; and RT, 3-Orhamnosyltransferase. Red colored words indicate that the compounds were detected in this study. 


\subsection{Extraction and HPLC Analysis of Anthocyanin}

To analyze the anthocyanin content, we extracted $100 \mathrm{mg}$ dried samples with $2 \mathrm{~mL}$ water:formic acid $(95: 5 v / v)$, and sonicated the solution for $20 \mathrm{~min}$. After centrifuging the sample at $12,000 \times g$ for $10 \mathrm{~min}$, the supernatant was filtered through a $0.45 \mu \mathrm{m}$ hydrophilic PTFE syringe filter $(\varnothing, 13 \mathrm{~mm}$, Advantec, Tokyo, Japan) in a brown vial. Anthocyanins were detected by Agilent 1200 series HPLC (Santa Clara, CA, USA) at a wavelength of $520 \mathrm{~nm}$ equipped with a Security Guard Cartridges Kit AQ C18 column (Phenomenex, Torrance, CA, USA) and a Synergi $4 \mu \mathrm{m}$ POLAR-RP 80A column $(250 \times 4.6 \mathrm{~mm}$ i.d., particle size $4 \mu \mathrm{m}$; Phenomenex, Torrance, CA, USA). The mobile phase consisted of a mixture of (A) water:formic acid (99.5:0.5, $v / v)$ and (B) acetonitrile:formic acid $(99.5: 0.5, v / v)$. The mobile phase program was set as follows: the reaction was started with $5 \%$ solvent $B$; was increased to $10 \%$ solvent B until 8 min; was increased to $13 \%$ solvent B until 13 min and was maintained until $15 \mathrm{~min}$; was increased to $15 \%$ solvent $\mathrm{B}$ until $18 \mathrm{~min}$ and maintained until $25 \mathrm{~min}$; was increased to $18 \%$ solvent B until $30 \mathrm{~min}$ and maintained until $35 \mathrm{~min}$; was increased to $21 \%$ solvent B until $40 \mathrm{~min}$ and maintained until $45 \mathrm{~min}$; and was then decreased to $5 \%$ solvent $\mathrm{B}$ at $45.1 \mathrm{~min}$ and maintained until $50 \mathrm{~min}$.

\subsection{Extraction and HPLC Analysis of Phenylpropanoid Compounds}

To analyze the phenylpropanoid content, we extracted $100 \mathrm{mg}$ dried powder with $2 \mathrm{~mL} 80 \%$ methanol, and sonicated the sample for $1 \mathrm{~h}$ at $37^{\circ} \mathrm{C}$. After centrifugation the sample at 12,000 rpm for $15 \mathrm{~min}$, the supernatant was filtered through a $0.45 \mu \mathrm{m}$ hydrophilic PTFE syringe filter $(\varnothing, 13 \mathrm{~mm}$, Advantec, Tokyo, Japan). Phenylpropanoids were detected using a Futecs model NS-4000 HPLC apparatus (Daejeon, Korea) equipped with a C18 column $(250 \times 4.6 \mathrm{~mm}, 5 \mu \mathrm{m}$; RStech, Daejeon, Korea) at a wavelength of $280 \mathrm{~nm}$. The mobile phase consisted of a mixture of (A) water:acetic acid (99.85:0.15 $v / v$ ) and (B) methanol. The initial mobile phase composition was as follows: $5 \%$ solvent B, followed by a linear gradient from $0 \%$ to $80 \%$ solvent B over $93 \mathrm{~min}$, which was then held at $5 \%$ solvent $\mathrm{B}$ for an additional $5 \mathrm{~min}$. The column was maintained at $30^{\circ} \mathrm{C}$, the flow rate was $1.0 \mathrm{~mL} / \mathrm{min}$, and the injection volume was $20 \mu \mathrm{L}$. Different compounds were quantified based on peak areas, and the concentrations were calculated as equivalents of representative standard compounds.

\subsection{Statistical Analysis}

Statistical analysis was performed with SPSS statistics 22 software (IBM Corp., Armonk, NY, USA) using Student's $t$ test or an analysis of variance (ANOVA) with Tukey's honestly significant difference test. All data are given as the mean values and standard deviation or standard error of triplicate experiments.

\section{Results}

\subsection{Phenotype of Tartary Buckwheat Plants under Salinity Stress}

To find out whether tartary buckwheat plants are influenced by salinity stress, we examined the phenotype of tartary buckwheat after 4 weeks of treatment with different concentrations of $\mathrm{NaCl}$ $(0,100,200$, and $300 \mathrm{mM})$ (Figure 2). Sensory evaluation showed no overall color change in tartary buckwheat under control and salt treatments. However, the development of tartary buckwheat treated by $\mathrm{NaCl}$ was decreased with an increase in $\mathrm{NaCl}$ concentration from 0 to $300 \mathrm{mM}$. At a $300 \mathrm{mM} \mathrm{NaCl}$ concentration, the leaves of tartary buckwheat were dry and the roots were greatly inhibited (Figure 2). 

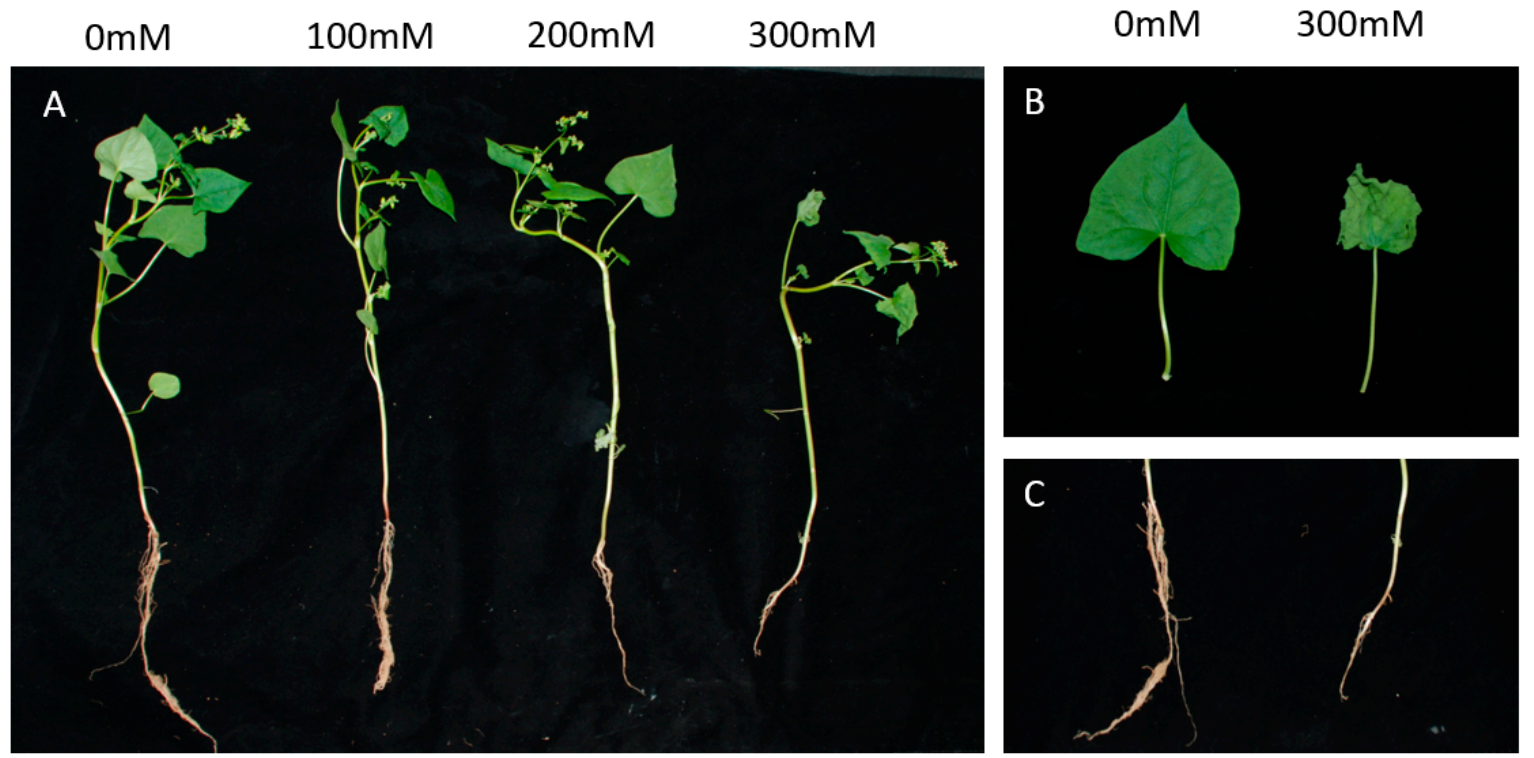

Figure 2. Morphology of whole plants (A), leaves (B), and roots (C) in response to salt stress.

\subsection{Analysis of Phenylpropanoid Content under Different $\mathrm{NaCl}$ Concentrations}

To investigate if the accumulation of phenolic compounds is influenced by salinity stress, we identified and quantified the phenolic compound contents under $\mathrm{NaCl}$ treatment by performing HPLC analysis. A total of eight phenolic compounds, namely, 4-hydroxybenzoic acid, chlorogenic acid, caffeic acid, ferulic acid, benzoic acid, rutin, trans-cinnamic acid, and quercetin, were identified and quantified (Table 1). Overall, 100 and $200 \mathrm{mM}$ salt treatment showed slightly more phenylpropanoid accumulation. In particular, the contents of phenolic acid, 4-hydroxybenzoic acid, benzoic acid, and trans-cinnamic acid, and flavonoids, namely, rutin and quercetin, were increased. The quantity of phenolic acid (4-hydroxybenzoic acid) accumulated was $0.17 \mathrm{mg} / \mathrm{g}$ at $200 \mathrm{mM}$ and was $1.17 \mathrm{folds}$ higher than the control. Additionally, the quantity of benzoic acid accumulated was $0.16 \mathrm{mg} / \mathrm{g}$ and was 1.25 folds higher than the control. The quantity of flavonoid (rutin) accumulated was $14.98 \mathrm{mg} / \mathrm{g}$ at $100 \mathrm{mM}$ and was 1.16 times higher than the control, and the quantity of quercetin accumulated was $0.15 \mathrm{mg} / \mathrm{g}$ and was 1.20 times higher than the control. On the other hand, chlorogenic acid, caffeic acid, and ferulic acid showed a tendency to decrease with salt treatment. The total phenylpropanoid content in tartary buckwheat was highest at a $100 \mathrm{mM} \mathrm{NaCl}$ concentration. This concentration can be of use for future time-treatment experiments. These results indicated that the accumulation of flavonoids in tartary buckwheat can be increased with $\mathrm{NaCl}$ treatment.

Table 1. The accumulation of phenolic compounds because of salinity stress in tartary buckwheat. (Average $\pm \mathrm{STDEV}, \mathrm{mg} / \mathrm{g}$ dry $\mathrm{wt}$.). The means and standard deviations were obtained from three independent experiments. Letters a-c indicate significant differences $(p<0.05)$.

\begin{tabular}{ccccc}
\hline Compound & $\mathbf{0 ~} \mathbf{~ M}$ & $\mathbf{1 0 0} \mathbf{~ M M}$ & $\mathbf{2 0 0} \mathbf{~ m M}$ & $\mathbf{3 0 0} \mathbf{~ m M}$ \\
\hline 4-hydroxy benzoic acid & $0.145 \pm 0.003 \mathrm{a}$ & $0.163 \pm 0.011 \mathrm{bc}$ & $0.170 \pm 0.011 \mathrm{c}$ & $0.153 \pm 0.006 \mathrm{ab}$ \\
Chlorogenic acid & $0.679 \pm 0.022 \mathrm{~b}$ & $0.638 \pm 0.034 \mathrm{~b}$ & $0.545 \pm 0.012 \mathrm{a}$ & $0.502 \pm 0.023 \mathrm{a}$ \\
Caffeic acid & $0.091 \pm 0.000 \mathrm{~b}$ & $0.088 \pm 0.011 \mathrm{~b}$ & $0.086 \pm 0.002 \mathrm{~b}$ & $0.059 \pm 0.004 \mathrm{a}$ \\
Ferulic acid & $0.015 \pm 0.000 \mathrm{~b}$ & $0.013 \pm 0.001 \mathrm{~b}$ & $0.013 \pm 0.001 \mathrm{~b}$ & $0.008 \pm 0.000 \mathrm{a}$ \\
Benzoic acid & $0.127 \pm 0.005 \mathrm{a}$ & $0.149 \pm 0.009 \mathrm{ab}$ & $0.159 \pm 0.008 \mathrm{~b}$ & $0.144 \pm 0.006 \mathrm{ab}$ \\
Rutin & $12.812 \pm 0.181 \mathrm{ab}$ & $14.981 \pm 0.150 \mathrm{~b}$ & $14.745 \pm 0.871 \mathrm{~b}$ & $11.108 \pm 0.512 \mathrm{a}$ \\
Trans-cinnamic acid & $0.012 \pm 0.001 \mathrm{a}$ & $0.014 \pm 0.001 \mathrm{ab}$ & $0.015 \pm 0.001 \mathrm{~b}$ & $0.012 \pm 0.000 \mathrm{a}$ \\
Quercetin & $0.129 \pm 0.005 \mathrm{~b}$ & $0.155 \pm 0.007 \mathrm{c}$ & $0.138 \pm 0.003 \mathrm{bc}$ & $0.108 \pm 0.001 \mathrm{a}$ \\
Kaempferol & $0.043 \pm 0.001 \mathrm{c}$ & $0.035 \pm 0.003 \mathrm{~b}$ & $0.034 \pm 0.001 \mathrm{~b}$ & $0.025 \pm 0.002 \mathrm{a}$ \\
Total & $14.057 \pm 1.906 \mathrm{~b}$ & $16.232 \pm 1.640 \mathrm{c}$ & $15.909 \pm 0.919 \mathrm{c}$ & $12.122 \pm 0.553 \mathrm{a}$ \\
\hline
\end{tabular}




\subsection{Analysis of Anthocyanin Content under Different $\mathrm{NaCl}$ Concentrations}

To investigate the accumulation of anthocyanin in tartar buckwheat under treatment with $\mathrm{NaCl}, \mathrm{HPLC}$ analysis was performed. Two anthocyanins, namely, cyanidin-3-O-glucoside and cyanidin-3-O-rutinoside, were identified and quantified (Table 2). The results in Table 2 show no significant change in anthocyanin content in tartar buckwheat under $\mathrm{NaCl}$ and control treatment. This result indicated that salt treatment does not affect the synthesis of anthocyanins in tartary buckwheat.

Table 2. The accumulation of anthocyanin under salinity stress in tartary buckwheat plants. (Average \pm STDEV, mg/g dry wt.). The means and standard deviations were obtained from three independent experiments. Letters a indicate significant differences $(p<0.05)$.

\begin{tabular}{ccccc}
\hline Compound & $\mathbf{0 ~} \mathbf{~ m M}$ & $\mathbf{1 0 0} \mathbf{~} \mathbf{M}$ & $\mathbf{2 0 0} \mathbf{~ m M}$ & $\mathbf{3 0 0} \mathbf{~ m M}$ \\
\hline Cyanidin 3-O-glucoside & $0.010 \pm 0.003 \mathrm{a}$ & $0.009 \pm 0.001 \mathrm{a}$ & $0.010 \pm 0.001 \mathrm{a}$ & $0.009 \pm 0.001 \mathrm{a}$ \\
Cyanidin 3-O-rutinoside & $0.095 \pm 0.012 \mathrm{a}$ & $0.091 \pm 0.007 \mathrm{a}$ & $0.081 \pm 0.004 \mathrm{a}$ & $0.094 \pm 0.004 \mathrm{a}$ \\
\hline
\end{tabular}

\subsection{Analysis of Phenylpropanoid Content by Varying the Time of Treatment with Salt}

To investigate effects of time of treatment on the accumulation of phenolic compounds in tartar buckwheat, in this experiment, we identified and quantified the phenolic compound contents by treatment with $100 \mathrm{mM} \mathrm{NaCl}$ for 2, 4, 6, and 8 days. Six phenolic acids were identified, including 4-hydroxybenzoic acid, chlorogenic acid, caffeic acid, ferulic acid, benzoic acid, and trans-cinnamic acid. Furthermore, three flavonoids were identified, namely, rutin, quercetin, and kaempferol (Table 3). The contents of phenolic compounds, except chlorogenic acid, caffeic acid, ferulic acid, and trans-cinnamic acid, increased under $\mathrm{NaCl}$ treatment. In particular, the contents of 4-hydroxybenzoic acid, benzoic acid, rutin, and quercetin were the highest on day 8 , which were $0.165,0.154,15.045$, and $0.155 \mathrm{mg} / \mathrm{g}$, respectively; they were 1.1, 1.28, 1.18, and 1.22 times higher than the control group, respectively. The total quantity of phenolic compounds slightly increased above 1.17 folds from $13.893 \mathrm{mg} / \mathrm{g}$ DW at day 2 when untreated to $16.264 \mathrm{mg} / \mathrm{g}$ DW at day 8 with salt treatment. The accumulation of total phenylpropanoids was the highest at day 8 after treatment and most of the phenylpropanoid content was higher than that in the control during the same period. These results suggest that the salt treatment of tartary buckwheat causes antioxidant activity improvement by inducing the accumulation of flavonoids and phenolic compounds.

Table 3. The accumulation of phenolic compounds under salt stress in tartary buckwheat plants (Average \pm STDEV, $\mathrm{mg} / \mathrm{g}$ dry weight.) The means and standard deviations were obtained from three independent experiments. Letters a-c indicate significant differences $(p<0.05)$.

\begin{tabular}{cccccc}
\hline Compound & NaCl & 2 Days & 4 Days & 6 Days & 8 Days \\
\hline $\begin{array}{c}\text { 4-hydroxy } \\
\text { benzoic acid }\end{array}$ & $0 \mathrm{mM}$ & $0.151 \pm 0.007 \mathrm{~b}$ & $0.150 \pm 0.007 \mathrm{~b}$ & $0.150 \pm 0.05 \mathrm{~b}$ & $0.150 \pm 0.007 \mathrm{~b}$ \\
\hline $\begin{array}{c}\text { Chlorogenic } \\
\text { acid }\end{array}$ & $00 \mathrm{mM}$ & $0.150 \pm 0.006 \mathrm{~b}$ & $0.156 \pm 0.005 \mathrm{ab}$ & $0.161 \pm 0.002 \mathrm{ab}$ & $0.165 \pm 0.005 \mathrm{a}$ \\
\hline \multirow{2}{*}{ Caffeic acid } & $100 \mathrm{mM}$ & $0.675 \pm 0.038 \mathrm{a}$ & $0.677 \pm 0.014 \mathrm{a}$ & $0.678 \pm 0.001 \mathrm{a}$ & $0.675 \pm 0.016 \mathrm{a}$ \\
& $0.674 \pm 0.042 \mathrm{a}$ & $0.664 \pm 0.014 \mathrm{ab}$ & $0.637 \pm 0.003 \mathrm{~b}$ & $0.631 \pm 0.010 \mathrm{~b}$ \\
\hline \multirow{2}{*}{ Ferulic acid } & $100 \mathrm{mM}$ & $0.091 \pm 0.006 \mathrm{a}$ & $0.088 \pm 0.002 \mathrm{a}$ & $0.086 \pm 0.004 \mathrm{a}$ & $0.087 \pm 0.005 \mathrm{a}$ \\
\hline \multirow{2}{*}{ Benzoic acid } & $0 \mathrm{mM}$ & $0.015 \pm 0.004 \mathrm{a}$ & $0.016 \pm 0.001 \mathrm{a}$ & $0.016 \pm 0.001 \mathrm{a}$ & $0.015 \pm 0.001 \mathrm{a}$ \\
& $100 \mathrm{mM}$ & $0.015 \pm 0.000 \mathrm{a}$ & $0.015 \pm 0.001 \mathrm{a}$ & $0.014 \pm 0.000 \mathrm{a}$ & $0.013 \pm 0.001 \mathrm{~b}$ \\
\hline \multirow{2}{*}{ Rutin } & $00 \mathrm{mM}$ & $0.120 \pm 0.004 \mathrm{c}$ & $0.122 \pm 0.003 \mathrm{c}$ & $0.122 \pm 0.004 \mathrm{c}$ & $0.120 \pm 0.007 \mathrm{c}$ \\
& $0 \mathrm{mM}$ & $0.120 \pm 0.004 \mathrm{c}$ & $0.133 \pm 0.001 \mathrm{~b}$ & $0.151 \pm 0.008 \mathrm{a}$ & $0.154 \pm 0.006 \mathrm{a}$ \\
\hline
\end{tabular}


Table 3. Cont.

\begin{tabular}{cccccc}
\hline Compound & $\mathbf{N a C l}$ & 2 Days & 4 Days & 6 Days & 8 Days \\
\hline Trans-cinnamic & $0 \mathrm{mM}$ & $0.012 \pm 0.000 \mathrm{~b}$ & $0.012 \pm 0.001 \mathrm{~b}$ & $0.012 \pm 0.001 \mathrm{~b}$ & $0.012 \pm 0.007 \mathrm{~b}$ \\
acid & $100 \mathrm{mM}$ & $0.012 \pm 0.000 \mathrm{~b}$ & $0.013 \pm 0.001 \mathrm{~b}$ & $0.014 \pm 0.000 \mathrm{a}$ & $0.015 \pm 0.001 \mathrm{a}$ \\
\hline \multirow{2}{*}{ Quercetin } & $0 \mathrm{mM}$ & $0.127 \pm 0.005 \mathrm{c}$ & $0.127 \pm 0.006 \mathrm{c}$ & $0.127 \pm 0.006 \mathrm{c}$ & $0.128 \pm 0.004 \mathrm{c}$ \\
& $100 \mathrm{mM}$ & $0.127 \pm 0.005 \mathrm{c}$ & $0.141 \pm 0.002 \mathrm{~b}$ & $0.150 \pm 0.007 \mathrm{ab}$ & $0.155 \pm 0.001 \mathrm{a}$ \\
\hline \multirow{2}{*}{ Kaempferol } & $0 \mathrm{mM}$ & $0.043 \pm 0.002 \mathrm{a}$ & $0.044 \pm 0.002 \mathrm{a}$ & $0.045 \pm 0.002 \mathrm{a}$ & $0.044 \pm 0.003 \mathrm{a}$ \\
& $100 \mathrm{mM}$ & $0.043 \pm 0.002 \mathrm{a}$ & $0.041 \pm 0.002 \mathrm{ab}$ & $0.037 \pm 0.004 \mathrm{bc}$ & $0.035 \pm 0.003 \mathrm{c}$ \\
\hline \multirow{2}{*}{ Total } & $0 \mathrm{mM}$ & $13.893 \pm 0.596 \mathrm{~b}$ & $13.919 \pm 0.605 \mathrm{~b}$ & $13.915 \pm 0.643 \mathrm{~b}$ & $13.954 \pm 0.571 \mathrm{~b}$ \\
& $100 \mathrm{mM}$ & $13.891 \pm 0.596 \mathrm{~b}$ & $14.545 \pm 0.214 \mathrm{~b}$ & $15.645 \pm 0.576 \mathrm{a}$ & $16.264 \pm 0.754 \mathrm{a}$ \\
\hline
\end{tabular}

\subsection{Analysis of Anthocyanin Content by Varying the Time of Treatment with Salt}

An analysis was conducted to investigate if the accumulation of anthocyanin is influenced by varying the time of treatment with $100 \mathrm{mM} \mathrm{NaCl}$. HPLC analysis was used to identify and quantify the anthocyanin content in tartary buckwheat under $100 \mathrm{mM} \mathrm{NaCl}$ treatment for 2, 4, 6, and 8 days (Table 4). Similar to the previous experiment mentioned in this article on different concentrations of $\mathrm{NaCl}$, here, both anthocyanins, namely, cyanidin-3-O-glucoside and cyanidin-3-O-rutinoside, were identified and quantified. However, the analysis showed that there was no significant change in the anthocyanin content. It can be seen that salt treatment does not affect the synthesis of anthocyanins.

Table 4. The accumulation of anthocyanins under salt stress in tartary buckwheat plants (Average \pm STDEV, $\mathrm{mg} / \mathrm{g}$ dry weight.). The means and standard deviations were obtained from three independent experiments. Letters $\mathrm{a}-\mathrm{b}$ indicate significant differences $(p<0.05)$.

\begin{tabular}{cccccc}
\hline Compound & $\mathbf{N a C l}$ & 2 Days & 4 Days & 6 Days & 8 Days \\
\hline \multirow{2}{*}{ Cyanidin 3-O-glucoside } & $0 \mathrm{mM}$ & $0.020 \pm 0.000 \mathrm{~b}$ & $0.017 \pm 0.001 \mathrm{ab}$ & $0.014 \pm 0.001 \mathrm{a}$ & $0.019 \pm 0.004 \mathrm{ab}$ \\
& $100 \mathrm{mM}$ & $0.017 \pm 0.000 \mathrm{ab}$ & $0.019 \pm 0.002 \mathrm{ab}$ & $0.017 \pm 0.000 \mathrm{ab}$ & $0.015 \pm 0.001 \mathrm{a}$ \\
\hline \multirow{2}{*}{ Cyanidin 3-O-rutinoside } & $0 \mathrm{mM}$ & $0.110 \pm 0.019 \mathrm{a}$ & $0.115 \pm 0.024 \mathrm{a}$ & $0.117 \pm 0.017 \mathrm{a}$ & $0.113 \pm 0.029 \mathrm{a}$ \\
& $100 \mathrm{mM}$ & $0.112 \pm 0.008 \mathrm{a}$ & $0.101 \pm 0.007 \mathrm{a}$ & $0.120 \pm 0.013 \mathrm{a}$ & $0.106 \pm 0.013 \mathrm{a}$ \\
\hline
\end{tabular}

\section{Discussion}

Salinity stress affects plants by reducing the water potential and causes ion imbalance or disturbances in ion homeostasis and toxicity. The detrimental effect is observed at the whole plant level as the death of plants or a decrease in productivity. Salt stress affects all the major processes, such as germination, growth, photosynthetic pigments and photosynthesis, water relation, nutrient imbalance, oxidative stress, and yield [30]. The salinity absorbed by the plant is concentrated in the old leaves. If the leaves continue to transport over a long time, the concentration of $\mathrm{Na}^{+}$and $\mathrm{Cl}^{-}$will eventually increase, and the leaves will die (Figure 2B). Besides the direct impact of salinity on plants, an ordinary result of salinity stress is the derivation of an excessive accumulation of reactive oxygen species (ROS). ROS are highly reactive and may cause cellular damage through the oxidation of lipids, proteins, and nucleic acids [31-33]. Salinity stress frequently causes both osmotic and ionic stress in plants, resulting in an increase or decrease of certain secondary metabolites in plants [3]. Navarro, Josefa M and colleagues [11] revealed that red peppers (Capsicum annuum L.) under moderate salinity exhibited increased total phenolic contents, but green and turning peppers displayed a decreased accumulation of total phenolic compounds. Ben Abdallah et al. [34] reported that black nightshade (Solanum nigrum L.) under salinity stress demonstrated increased total phenolic contents and carotenoids using HPLC analysis. Additionally, flavonoid- and carotenoid-gene expression in salinity-treated plants were higher than in the non-treated control. Lim et al. [35] investigated the influence of salinity stress on carotenoids and phenolic compounds in common buckwheat (Fagopyrum esculentum) sprout, not tartary buckwheat (Fagopyrum tataricum). They also found no significant change of color in common 
buckwheat sprouts. The carotenoid content of sprouts treated with 50 and $100 \mathrm{mM} \mathrm{NaCl}$ after 7 days of cultivation was two times higher than that of the control $(0 \mathrm{mM} \mathrm{NaCl})$. Moreover, the total phenolic content of sprouts increased in response to increasing $\mathrm{NaCl}$ concentrations, with the exception of 200 $\mathrm{mM} \mathrm{NaCl}$. In particular, 50 and $100 \mathrm{mM} \mathrm{NaCl}$ after 7 days was about two times higher than the control. Similar to the total phenolic content of sprouts by $\mathrm{NaCl}$ treatment, the radical scavenging activity of the sprouts increased in response to increasing $\mathrm{NaCl}$ concentrations

There are many studies on the relationship between abiotic stress and secondary metabolites in buckwheat. Jeon et al. [36] investigated the correlation between cold stress and secondary metabolism in tartary buckwheat. The contents of cyanidin 3-0-glucosid and cyanidin 3-0-rutinoside were increased under cold stress, and the contents of epicatechin and catechin were also increased. Additionally, the radical scavenging activity of the not-treated tartary buckwheat was not changed, but the radical scavenging activity was five times higher in cold-treated tartary buckwheat. Yoko Tsurunaga and colleagues [37] reported the relationship between various light conditions and secondary metabolites in common buckwheat. In particular, common buckwheat sprouts under irradiation with UV-B > $300 \mathrm{~nm}$ increased the levels of DPPH radical scavenging activity, rutin, and anthocyanin, but the growth of buckwheat sprouts under irradiation with UV-B 260-280 nm was detrimental, exhibiting yellowing or withering. Tatsuro Suzuki et al. [38] investigated the effect of UV-B radiation, cold, and desiccation in tartary buckwheat leaves. The content of rutin was increased by UV-B radiation and desiccation treatment, and rutin glucosidase activity was also increased by UV-B radiation, cold, and desiccation. These results suggested that rutin and rutin glucosidase activity may be related to the defense system against abiotic stress conditions.

In this study, we investigated the influence of salinity in tartary buckwheat plants by using HPLC analysis. The change of color was observed to not be significant in the salt treatment experiment in tartary buckwheat. Just as the color did not change in plants under $\mathrm{NaCl}$ treatment, the accumulation of anthocyanin was also not affected. However, the accumulation of phenolic compounds increased slightly in response to the $\mathrm{NaCl}$ concentration, except under $300 \mathrm{mM} \mathrm{NaCl}$ treatment. In particular, rutin, the most tartary buckwheat-containing flavonoid, increased the most. Furthermore, 4-hydroxy benzoic acid, benzoic acid, trans-cinnamic acid, and quercetin were increased, but chlorogenic acid, caffeic acid, ferulic acid, and kaempferol were decreased. Based on previously reported research and this experiment using salinity treatment in tartary buckwheat, we suggest that salinity plays a role in the acceleration of phenolic compound synthesis in tartary buckwheat to protect against salinity-induced oxidative damages. However, the antioxidant activity and mechanism of salt stress in tartary buckwheat have not yet been elucidated, so further research involving GC-TOFMS (gas chromatography time-of-flight mass spectrometry), DPPH scavenging assays, and an analysis of the carotenoid content is needed.

\section{Conclusions}

In this study, we investigated the phenylpropanoid content in tartary buckwheat in response to salinity stress. After $\mathrm{NaCl}$ treatment, there was no change in the accumulation of anthocyanin and the color of tartary buckwheat. However, the accumulation of phenolic compounds increased in response to the $\mathrm{NaCl}$ concentration. Rutin, 4-hydroxy benzoic acid, benzoic acid, trans-cinnamic acid, and quercetin were increased, but chlorogenic acid, caffeic acid, ferulic acid, and kaempferol were decreased. Previous studies have reported that phenylpropanoids are influenced by abiotic stress, such as cold and UV-irradiation, supporting the findings of the current study. These data provide functional information about secondary metabolites in tartary buckwheat under abiotic stress and may be useful for studying secondary metabolites in other plants.

Author Contributions: S.U.P. designed the experiments and analyzed the data. N.S.K., S.-J.K., D.M.C., J.J., and J.S.P. performed the experiments and analyzed the data. N.S.K., S.-J.K., and D.M.C. wrote the manuscript. All authors read and approved the final manuscript.

Funding: This research was supported by grants from the Research Program of KAERI, Korea. 
Acknowledgments: Authors are grateful to the Korea Institute of Planning and Evaluation for Technology in Food, Agriculture, Forestry and Fisheries (IPET) through the Agri-Bio Industry Technology Development Program funded by the Ministry of Agriculture, Food and Rural Affairs (MAFRA) (317005-04-3) for supporting this work.

Conflicts of Interest: The authors declare no conflicts of interest.

\section{References}

1. Munns, R.; Tester, M. Mechanisms of salinity tolerance. Annu. Rev. Plant Biol. 2008, 59, 651-681. [CrossRef] [PubMed]

2. Yeo, A.R.; Flowers, T.J. Salinity Resistance in Rice (Oryza sativa L.) And a Pyramiding Approach to Breeding Varieties for Saline Soils. Aust. J. Plant Physiol. 1986, 13, 161-173. [CrossRef]

3. Glenn, E.P.; Brown, J.J.; Blumwald, E. Salt tolerance and crop potential of halophytes. Crit. Rev. Plant Sci. 1999, 18, 227-255. [CrossRef]

4. Mahajan, S.; Tuteja, N. Cold, salinity and drought stresses: An overview. Arch. Biochem. Biophys. 2005, 444, 139-158. [CrossRef] [PubMed]

5. Parida, A.K.; Das, A.B. Salt tolerance and salinity effects on plants: A review. Ecotoxicol. Environ. Saf. 2005, 60, 324-349. [CrossRef] [PubMed]

6. Daneshmand, F.; Arvin, M.J.; Kalantari, K.M. Physiological responses to $\mathrm{NaCl}$ stress in three wild species of potato in vitro. Acta Physiol. Plant. 2010, 32, 91. [CrossRef]

7. Petrusa, L.M. Proline status in salt-tolerant and salt-sensitive alfalfa cell lines and plants in response to $\mathrm{NaCl}$. Plant Physiol. Biochem. 1997, 35, 8.

8. Dixon, R.A.; Paiva, N.L. Stress-Induced Phenylpropanoid Metabolism. Plant Cell 1995, 7, $1085-1097$. [CrossRef] [PubMed]

9. Pedranzani, H.; Racagni, G.; Alemano, S.; Miersch, O.; Ramírez, I.; Peña-Cortés, H.; Taleisnik, E.; Machado-Domenech, E.; Abdala, G. Salt tolerant tomato plants show increased levels of jasmonic acid. Plant Growth Regul. 2003, 41, 149-158. [CrossRef]

10. Muthukumarasamy, M.; Gupta, S.D.; Panneerselvam, R. Enhancement of Peroxidase, Polyphenol Oxidase and Superoxide Dismutase Activities by Triadimefon in $\mathrm{NaCl}$ Stressed Raphanus Sativus L. Biol. Plant. 2000, 43, 317-320. [CrossRef]

11. Navarro, J.M.; Flores, P.; Garrido, C.; Martinez, V. Changes in the contents of antioxidant compounds in pepper fruits at different ripening stages, as affected by salinity. Food Chem. 2006, 96, 66-73. [CrossRef]

12. Dietrych-Szostak, D.; Oleszek, W. Effect of Processing on the Flavonoid Content in Buckwheat (Fagopyrum esculentum Möench) Grain. J. Agric. Food Chem. 1999, 47, 4384-4387. [CrossRef] [PubMed]

13. Oomah, B.D.; Mazza, G. Flavonoids and Antioxidative Activities in Buckwheat. J. Agric. Food Chem. 1996, 44, 1746-1750. [CrossRef]

14. Kitabayashi, H.; Ujihara, A.; Hirose, T.; Minami, M. On the Genotypic Differences for Rutin Content in Tartary Buckwheat, Fagopyrum tataricum Gaertn. Jpn. J. Breed. 1995, 45, 189-194. [CrossRef]

15. Fabjan, N.; Rode, J.; Košir, I.J.; Wang, Z.; Zhang, Z.; Kreft, I. Tartary Buckwheat (Fagopyrum tataricum Gaertn.) as a Source of Dietary Rutin and Quercitrin. J. Agric. Food Chem. 2003, 51, 6452-6455. [CrossRef] [PubMed]

16. Kim, S.J.; Kawaharada, C.; Suzuki, T.; Saito, K.; Hashimoto, N.; Takigawa, S.; Noda, T.; Matsuura-endo, C.; Yamauchi, H. Effect of Natural Light Periods on Rutin, Free Amino Acid and Vitamin C Contents in the Sprouts of Common (Fagopyrum esculentum Moench) and Tartary (F. tataricum Gaertn.) Buckwheats. Food Sci. Technol. Res. 2006, 12, 199-205. [CrossRef]

17. Barros, J.; Serrani-Yarce, J.C.; Chen, F.; Baxter, D.; Venables, B.J.; Dixon, R.A. Role of bifunctional ammonia-lyase in grass cell wall biosynthesis. Nat. Plants 2016, 2, 16050. [CrossRef] [PubMed]

18. Vogt, T. Phenylpropanoid biosynthesis. Mol. Plant 2010, 3, 2-20. [CrossRef] [PubMed]

19. Lepiniec, L.; Debeaujon, I.; Routaboul, J.M.; Baudry, A.; Pourcel, L.; Nesi, N.; Caboche, M. Genetics and biochemistry of seed flavonoids. Annu. Rev. Plant Biol. 2006, 57, 405-430. [CrossRef] [PubMed]

20. Saito, K.; Yonekura-Sakakibara, K.; Nakabayashi, R.; Higashi, Y.; Yamazaki, M.; Tohge, T.; Fernie, A.R. The flavonoid biosynthetic pathway in Arabidopsis: Structural and genetic diversity. Plant Physiol. Biochem. PPB 2013, 72, 21-34. [CrossRef] [PubMed] 
21. Routaboul, J.M.; Dubos, C.; Beck, G.; Marquis, C.; Bidzinski, P.; Loudet, O.; Lepiniec, L. Metabolite profiling and quantitative genetics of natural variation for flavonoids in Arabidopsis. J. Exp. Bot. 2012, 63, 3749-3764. [CrossRef] [PubMed]

22. Falcone Ferreyra, M.L.; Rius, S.P.; Casati, P. Flavonoids: Biosynthesis, biological functions, and biotechnological applications. Front. Plant Sci. 2012, 3, 222. [CrossRef] [PubMed]

23. Hichri, I.; Barrieu, F.; Bogs, J.; Kappel, C.; Delrot, S.; Lauvergeat, V. Recent advances in the transcriptional regulation of the flavonoid biosynthetic pathway. J. Exp. Bot. 2011, 62, 2465-2483. [CrossRef] [PubMed]

24. Nakabayashi, R.; Yonekura-Sakakibara, K.; Urano, K.; Suzuki, M.; Yamada, Y.; Nishizawa, T.; Matsuda, F.; Kojima, M.; Sakakibara, H.; Shinozaki, K.; et al. Enhancement of oxidative and drought tolerance in Arabidopsis by overaccumulation of antioxidant flavonoids. Plant J. Cell Mol. Biol. 2014, 77, 367-379. [CrossRef] [PubMed]

25. Zhang, Y.; Butelli, E.; Martin, C. Engineering anthocyanin biosynthesis in plants. Curr. Opin. Plant Biol. 2014, 19, 81-90. [CrossRef] [PubMed]

26. Hernández, I.; Alegre, L.; Breusegem, F.; Munné-Bosch, S. How relevant are flavonoids as antioxidants in plants? Trends Plant Sci. 2009, 14, 125-132. [CrossRef] [PubMed]

27. Buer, C.S.; Kordbacheh, F.; Truong, T.T.; Hocart, C.H.; Djordjevic, M.A. Alteration of flavonoid accumulation patterns in transparent testa mutants disturbs auxin transport, gravity responses, and imparts long-term effects on root and shoot architecture. Planta 2013, 238, 171-189. [CrossRef] [PubMed]

28. Doughty, J.; Aljabri, M.; Scott, R.J. Flavonoids and the regulation of seed size in Arabidopsis. Biochem. Soc. Trans. 2014, 42, 364-369. [CrossRef] [PubMed]

29. Xu, W.; Dubos, C.; Lepiniec, L. Transcriptional control of flavonoid biosynthesis by MYB-bHLH-WDR complexes. Trends Plant Sci. 2015, 20, 176-185. [CrossRef] [PubMed]

30. Parihar, P.; Singh, S.; Singh, R.; Singh, V.P.; Prasad, S.M. Effect of salinity stress on plants and its tolerance strategies: A review. Environ. Sci. Pollut. Res. Int. 2015, 22, 4056-4075. [CrossRef] [PubMed]

31. Apel, K.; Hirt, H. Reactive oxygen species: Metabolism, oxidative stress, and signal transduction. Annu. Rev. Plant Biol. 2004, 55, 373-399. [CrossRef] [PubMed]

32. Ahmad, P.; Jaleel, C.A.; Azooz, M.M.; Nabi, G. Generation of ROS and Non-Enzymatic Antioxidants During Abiotic Stress in Plants. Bot. Res. Int. 2009, 2, 11-20.

33. Ahmad, P.; Jaleel, C.A.; Salem, M.A.; Nabi, G.; Sharma, S. Roles of enzymatic and nonenzymatic antioxidants in plants during abiotic stress. Crit. Rev. Biotechnol. 2010, 30, 161-175. [CrossRef] [PubMed]

34. Abdallah, S.B.; Aung, B.; Amyot, L.; Lalin, I.; Lachâal, M.; Karray-Bouraoui, N.; Hannoufa, A. Salt stress $(\mathrm{NaCl})$ affects plant growth and branch pathways of carotenoid and flavonoid biosyntheses in Solanum nigrum. Acta Physiol. Plant. 2016, 38, 72. [CrossRef]

35. Lim, J.H.; Park, K.J.; Kim, B.K.; Jeong, J.W.; Kim, H.J. Effect of salinity stress on phenolic compounds and carotenoids in buckwheat (Fagopyrum esculentum M.) sprout. Food Chem. 2012, 135, 1065-1070. [CrossRef] [PubMed]

36. Jeon, J.; Kim, J.K.; Wu, Q.; Park, S.U. Effect of cold stress on transcripts and metabolites in tartary buckwheat(Fagopyrum tataricum). Environ. Exp. Bot. 2018, 155, 488-496. [CrossRef]

37. Tsurunaga, Y.; Takahashi, T.; Katsube, T.; Kudo, A.; Kuramitsu, O.; Ishiwata, M.; Matsumoto, S. Effects of UV-B irradiation on the levels of anthocyanin, rutin and radical scavenging activity of buckwheat sprouts. Food Chem. 2013, 141, 552-556. [CrossRef] [PubMed]

38. Suzuki, T.; Honda, Y.; Mukasa, Y. Effects of UV-B radiation, cold and desiccation stress on rutin concentration and rutin glucosidase activity in tartary buckwheat (Fagopyrum tataricum) leaves. Plant Sci. 2005, 168, 1303-1307. [CrossRef]

(C) 2019 by the authors. Licensee MDPI, Basel, Switzerland. This article is an open access article distributed under the terms and conditions of the Creative Commons Attribution (CC BY) license (http://creativecommons.org/licenses/by/4.0/). 